\section{Kim Williams}

Kim Williams Books

Corso Regina Margherita, 72

10153 Turin (Torino) ITALY

kwb@kimwilliamsbooks.com

\section{Persian Architecture and Mathematics}

Abstract. NNJ editor-in-chief Kim Williams introduces the papers in NNJvol. 14, no. 2 (Autumn 2012).

For some years now, each issue of the Nexus Network Journal contains a group of articles focussing on a single topic, complemented by other research, book and article reviews and conference reports. This arrangement allows us to collect groups of related papers in order to constitute an anthology capable of becoming significant research resource for those pursuing a certain topic, and to allow the journal to function as journals usually do, publishing new research in the field of architecture and mathematics as a whole in a timely fashion so that new findings reach their intended readership.

This present issue of the NNJ, dedicated to Persian architecture and mathematics, grew out of a dialogue between Reza Sarhangi, director of the Bridges conferences for art and mathematics, and myself. I was particularly happy when Reza accepted my invitation to guest edit an issue of the $N N J$, because he was the author of a paper on this topic that appeared in the very first issue of the journal, in 1999, so his participation represents a special kind of on-going collaboration. In his turn, Reza selected an Editorial Committee composed of a group of scholars familiar with Persian architecture and mathematics, which included Carol Bier, Lynn Bodner, Douglas Dunham, Mohammad Gharipour, and Hooman Koliji, who played an active and valuable role in reviewing and selecting the papers received as a result of the Call for Papers, and editing those selected for publication. I am very grateful to all of them for their gifts of time and effort.

Reza's Letter from the Guest Editor, entitled "Persian Architecture and Mathematics: An Overview" provides a helpful introduction to Persian architecture and mathematics, as well as a good outline of the group of papers that make up this issue, contributed by Alain Juhel; Mahsa Kharazmi, Reza Afhami and Mahmood Tavoosic; Carol Bier, Maryam Ashkan and Yahaya Ahmad; Hooman Koliji, B. Lynn Bodner, Carl Bovill, and Reza Sarhangi himself. Also included is a glossary of special terms that appear in the issue.

The issue is completed by a pair of other research papers which describe the geometry and proportions of important monuments in Italy and Iran built around the same period of time: the fifteenth century. Giampiero Mele has analyzed the urban fabric contained within the city walls of the town of Acaya, in Italy's Apulia region, an analysis made possible by a new integrated survey involving manual, topographical, photogrammetric and $3 \mathrm{D}$ laserscan techniques. His research has allowed him to shed new light on how the town was originally laid out and then changed over the ensuing centuries. In a similar vein, on the basis of his own careful survey, Mojtaba Pour Ahmadi has analyzed the mausoleum of Sheikh Zāhed-e Gīlāni in northern Iran in order to shed light on how the unusual dome of the building might have been designed. Although it will come as no surprise to readers of the $N N J$, finding geometric techniques used to design works of architecture and urban design in very different cultures underlines the universality of geometry, and the intimate relationships between architecture and mathematics.

As I write this, we are very close to time for our biennial Nexus conference on architecture and mathematics: Nexus 2012: Relationships Between Architecture and 
Mathematics, to take place in Milan, Italy, 11-14 June 2012. The next two issues of the $N N J$ will feature papers presented at the conference.

I hope you enjoy this very special issue of the NNJ as much as I did!

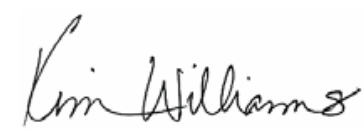

\section{About the author}

Kim Williams is the director of the conference series "Nexus: Relationships Between Architecture and Mathematics" and the founder of the Nexus Network Journal. 